\title{
Quality Characteristics and Oxidative Stability of Date Seed Oil During Storage
}

\author{
S. Besbes,${ }^{1 *}$ C. Blecker,${ }^{3}$ C. Deroanne,${ }^{3}$ G. Lognay,${ }^{4}$ N.-E. Drira,${ }^{2}$ H. Attia ${ }^{1}$
}

\begin{abstract}
'Unité Analyses Alimentaires, Ecole Nationale d'Ingénieurs de Sfax, Route de Soukra 3038 Sfax, Tunisia, ${ }^{2}$ Laboratoire deBiotechnologie Végétale, Faculté des Sciences de Sfax, Route de Soukra 3038 Sfax, Tunisia ${ }^{3}$ Unité de Technologie des Industries Agro-alimentaires, Faculté Universitaire des Sciences Agronomiques de Gembloux, passage des Déportés 2, 5030 Gembloux, Belgium

${ }^{4}$ Unité de Chimie Générale et Organique, Faculté Universitaire des Sciences Agronomiques de Gembloux, passage des Déportés 2, 5030 Gembloux, Belgium
\end{abstract}

\begin{abstract}
Studies were conducted on some quality characteristics of date seed oil from two date palm cultivars (Phoenix dactylifera L.): Deglet Nour and Allig. The following values were obtained for Deglet Nour and Allig cultivars respectively: unsaponifiable matter $8.92-7.76 \%$, iodine value $45.49-44.08$, total phenols $520.81-220.32 \mu \mathrm{g} / \mathrm{g}$ oil, chlorophylls $0.86-0.58 \mu \mathrm{g} / \mathrm{g}$ oil, viscosity $18.50-20.50 \mathrm{mPa} . \mathrm{s}$, refractive index 1.457-1.462, acidity $1.06-2.10 \mathrm{mg} \mathrm{KOH} / \mathrm{g}$ oil and peroxide index $16.00-25.00 \mathrm{meq} \mathrm{O}_{2} / 100 \mathrm{~g}$ oil. Lipid fractionation of date seed oil yielded $98.30-97.30 \%$ neutral lipids, $97.26-96.90 \%$ triglycerides, $0.25-0.18 \%$ phospholipids and $0.36-0.31 \%$ sterols. Gas-liquid chromatography revealed that the major unsaturated fatty acid was oleic acid (39.17-42.13\%) while the main saturated fatty acid was lauric acid (24.34-22.56\%). Date seed oil showed high medium molecular weight triglycerides (C32-C42, about $27 \%$ ). Extinction coefficients at $232 \mathrm{~nm}$ and $270 \mathrm{~nm}$ increased slightly during 40 days in oven $\left(60^{\circ} \mathrm{C}\right)$ showing that date seed oil could be easily stored. The production of oil from date seeds provides the use of a renewable resource, and at the same time adding value to agricultural products.
\end{abstract}

Key Words: date seeds, oil, quality, oxidation, storage

\section{INTRODUCTION}

Date seeds (Phoenix dactylifera L.) may have extractable high-value-added components. However very little use has been made of these pits, rather, they are discarded or used in animal feed. Few works have been undertaken on date palm seeds, focused particularly in their chemical composition (El-Shurafa et al., 1982; Al-Showiman, 1990; Devshony et al. 1992; AlHooti et al., 1998; Hamada et al., 2002). Pits of the date palm are a waste product of many industries based on the technological transformation of the date fruits or on their biological transformation (Besbes et al., 2004). Then, a large quantity of date seeds could be easily collected from the date processing industries or from the

*To whom correspondence should be sent (e-mail: besbes.s@voila.fr).

Received 1 March 2004; revised 20 April 2004.

Food Sci Tech Int $\quad 2004 ; 10(5): 333-338$

(c) 2004 Sage Publications

ISSN: $1082-0132$

DOI: $10.1177 / 1082013204047777$ waste products (representing nearly $30 \%$ of the production in Tunisia) coming either directly from the palm grove or from the gap-conditioning stations. Date pits, a low-cost agricultural by-product, was a good precursor of the production of activated carbons which are the most popular used adsorbents (Girgis and ElHendawy, 2002; Banat et al., 2003). Some minor molecules, such as a water-soluble galactomannan and an alkali-soluble heteroxylan were extracted from date seeds and then characterised (Ishrud et al., 2001; Ishrud et al., 2003).

It is well known that the average weight of date pits is about $10-15 \%$ of date weight (Almana and Mahmoud, 1994; Hussein et al., 1998). In Tunisia, lipid fraction of date seed could amount to over 1000 tons annually, assuming a mean proportion of $10 \%$ of seed in date fruit and $10 \%$ oil content of seeds. In a previous paper we reported that the oxidative stability of date seed oils, measured by Rancimat, was higher than that of most vegetable oils and comparable to that of olive oil; they can also protect against UV light responsible for most cellular damage (Besbes et al., 2004).

The aim of this work was to determine some quality characteristics of date seed oils and to study the effect 
in their oxidation of storage in accelerated conditions $\left(60^{\circ} \mathrm{C}\right)$ to evaluate the potential use of date seeds as a new source of lipids for human uses.

\section{MATERIALS AND METHODS}

\section{Samples}

The seeds of the two cultivars: Deglet Nour and Allig were directly sampled from $50 \mathrm{~kg}$ of waste date fruit having the same origin (National institute of Arid Zone Degach, Tunisia) and collected at Tamr stage (full ripeness). The seeds were soaked in water, washed to free them of any adhering date flesh, airdried and then dried $(12 \mathrm{~h})$ at about $50^{\circ} \mathrm{C}$. Date pits, from each variety, were separately milled in a heavyduty grinder to pass $1-2 \mathrm{~mm}$ screens and then preserved at $-20^{\circ} \mathrm{C}$ until analyses.

\section{Methods}

\section{Lipid Extraction and Preservation}

Lipid extraction was carried out with an SER 148 solvent extractor (Velp Scientifica, Europe) equipped with 6 Soxhlet posts. About $15 \mathrm{~g}$ of powdered date seeds were used for each oil extraction with petroleum ether $\left(40-60^{\circ} \mathrm{C}\right.$, Merck). The operational conditions were (Besbes et al., 2004): $30 \mathrm{~min}$ immersion time with thimble immersed in boiling solvent. Washing time: 60 min of reflux washing.

The obtained seed oils were drained under a stream of nitrogen and then stored in a freezer $\left(-20^{\circ} \mathrm{C}\right)$ for subsequent analyses.

\section{Physico-Chemical Analyses}

AOCS official methods (AOCS, 1997) were used for the determination of the unsaponifiable matter (Method Ca 6b-53), acididy (method Cd 3d-63), iodine value (method $\mathrm{Cd} 1-25$ ) and peroxide value (method Cd 8-53).

The refractive index was determined using an Abbe refractometer (Bellingham \& Stanley Ltd, United Kingdom) at $20^{\circ} \mathrm{C}$.

K232 and K270 extinction coefficients were calculated from absorption at $232 \mathrm{~nm}$ and $270 \mathrm{~nm}$ respectively, with a UV spectrophotometer (HewlettPackard, HP 8452 A) using a $1 \%$ solution of oil in cyclohexane and path length of $1 \mathrm{~cm}$ (AOAC, 1997).

Total phenols, expressed as cafeic acid ( $\mu \mathrm{g} / \mathrm{g}$ of oil) were determined at $725 \mathrm{~nm}$ using Folin-Ciocalteau reagent as described by Salvador et al. (2003).

Chlorophyll content was determined according to Cc 13d-55 method (AOAC, 1997).

Viscosity was followed at $25^{\circ} \mathrm{C}$ with stress Tech
Rheologica Rheometer (Rheologica Instruments AB, Lund, Sweden) conducted with a steel cone-plate (C $40 / 4$ ) under a constant shear rate of $100 \mathrm{~s}^{-1}$.

Lipid class separation was done according to Vaghela and Kilara (1995) with few modifications. Separation was performed using SPE cartridges, aminopropylsilica $\left(\mathrm{NH}_{2}\right)$ and octadecylsilica (C18) (Mega Bond Elut) activated before use by rinsing with $20 \mathrm{~mL}$ hexane, preventing the column from drying out. The oil sample was diluted in $2 \mathrm{~mL}$ of chloroform and then placed onto the column. Lipid classes were recovered by sequential elution with $18 \mathrm{~mL}$ each of $\mathrm{CHCl}_{3} /$ Isopropanol (2:1), $\mathrm{Et}_{2} \mathrm{O} /$ acetic acid (98:2), and $\mathrm{MeOH}$ to separate neutral lipids, free fatty acids and phospholipids, respectively. Neutral lipids classes were then recovered by sequential elution with $12 \mathrm{~mL}$ hexane, $36 \mathrm{~mL}$ hexane $/ \mathrm{MeCl}_{2} / \mathrm{Et}_{2} \mathrm{O}(89: 10: 1), 36 \mathrm{~mL}$ hexane/ ethyl acetate $(95: 5), 36 \mathrm{~mL}$ hexane/ethyl acetate (85: 15), $18 \mathrm{~mL} \mathrm{CHCl}_{3} / \mathrm{MeOH}(2: 1)$ to separate steryl esters, triglycerides, sterols, diglycerides and monoglycerides, respectively. The different lipid classes were evaporated at $40{ }^{\circ} \mathrm{C}$ under reduced pressure and then classes content were expressed as percentage of total lipids. Sample were analysed in triplicate by reusing the same SPE column. Before reuse, the column was rinsed with $20 \mathrm{~mL}$ of acetone and then dried by passing nitrogen through it.

Fatty acids composition was determined using Hewlett-Packard 5890 Series II gas chromatograph (HP co., Amsterdam, the Netherlands) as described in a previous paper (Besbes et al., 2004).

Triglycerides groups were separated by gas chromatography according to Ce 5-86 method approved by the Association of Official Analytical Chemists (AOAC, 1997). The triglycerides analyses were performed on Hewlett-Packard 5890 gas chromatograph (HP co., Amsterdam, the Netherlands) equipped with flame ionisation detector (FID) and a fused silicated column (65\% phenyl, $35 \%$ methylpolysiloxane, $25 \mathrm{~m} \times$ $0.25 \mathrm{~mm} \times 0.10 \mu \mathrm{m}$ film thickness). The oven temperature was programmed from $220^{\circ} \mathrm{C}$ to $350^{\circ} \mathrm{C}$ at $4{ }^{\circ} \mathrm{C} / \mathrm{min}$ and the injector and the detector temperatures were set at $350^{\circ} \mathrm{C}$ and $380^{\circ} \mathrm{C}$ respectively. Nitrogen was the carrier gas ( 1 bar). The peak areas of duplicate injections were measured with an HP computing integrator. Values were the average of two determinations.

\section{Oven Test}

Twenty samples $(20 \mathrm{~g})$ of each date seed oil variety were poured into separate $50 \mathrm{~mL}$ open beakers $(4 \mathrm{~cm}$ diameter, $6 \mathrm{~cm}$ height) without stirring, and then kept in the dark in an oven at $60 \pm 1{ }^{\circ} \mathrm{C}$. The temperature of $60^{\circ} \mathrm{C}$ is used as a rapid method to simulate the storage in real conditions (Nissiotis and Tasioula-Margari, 2002). One sample from each variety was randomly 
removed from the oven at a predetermined time, cooled at room temperature $(15 \mathrm{~min})$ and then analysed for specific extinctions at $232 \mathrm{~nm}$ and $270 \mathrm{~nm}$ and chlorophylls content.

\section{RESULTS AND DISCUSSION}

\section{Date Seed Oil's Quality Indices}

The relative percentage weight of lipids compared with weight of dried pits was about $10.19 \%$ for Deglet Nour cultivar and about $12.67 \%$ for Allig cultivar (Besbes et al., 2004). The physico-chemical quality parameters (Table 1) were generally similar to those cited by Hamada et al. (2002) and El-Shurafa et al. (1982), but higher than those reported by Devshony et al. (1992).

Deglet Nour seed oil contained slightly more unsaponifable matter and chlorophylls than Allig seed oil $(0.89 \%$ against $0.77 \%$ and $0.86 \mu \mathrm{g} / 100 \mathrm{~g}$ against $0.58 \mu \mathrm{g} / 100 \mathrm{~g}$, respectively). The oil obtained from Deglet Nour seeds contained near $60 \%$ more total phenols than that obtained from Allig seeds $(520.8 \mathrm{mg} / \mathrm{kg}$ against $220.3 \mathrm{mg} / \mathrm{kg})$. This seemed to be the principal cause of the higher oxidative stability reported in a recent study ( $44 \mathrm{~h}$ against $33 \mathrm{~h}$ determined by Rancimat) of Deglet Nour seed oil (Besbes et al., 2004). A high correlation was observed between total polyphenol content and oxidative stability of olive oil (Papadopoulus and Boskow, 1991; Montedoro et al., 1993; Caponio et al., 1999; Salvador et al., 2001). It is worth noting that date seed oil has a higher phenol content compared to most edible oil except olive oil which was particularly considered as a source of phenolic compounds in Mediterranean diet. It has been reported that the phenol compounds content in olive

Table 1. Quality indices of date seed oils.

\begin{tabular}{|c|c|c|}
\hline \multirow{3}{*}{ Quaity Indices ${ }^{a}$} & \multicolumn{2}{|c|}{ Cultivars } \\
\hline & Deglet Nour & Allig \\
\hline & \multicolumn{2}{|c|}{ (Mean $\pm \mathrm{SD}, n=3$ ) } \\
\hline Unsaponfiable matter $(\mathrm{g} / \mathrm{kg})$ & $8.92 \pm 0.39$ & $7.76 \pm 0.34$ \\
\hline Chlorophylls ( $\mu \mathrm{g} / \mathrm{g})$ & $0.86 \pm 0.05$ & $0.58 \pm 0.07$ \\
\hline Total phenols $(\mu \mathrm{g} / \mathrm{g})$ & $520.8 \pm 10.2$ & $220.3 \pm 6.3$ \\
\hline Refractive index (at $20^{\circ} \mathrm{C}$ ) & $1.457 \pm 0.001$ & $1.462 \pm 0.001$ \\
\hline Viscosity (mPa.s) & $18.50 \pm 0.50$ & $20.50 \pm 0.30$ \\
\hline Acid value (mg KOH/g oil) & $1.06 \pm 0.06$ & $2.10 \pm 0.14$ \\
\hline Free fatty acids (\% oleic acid) & $0.53 \pm 0.03$ & $1.05 \pm 0.07$ \\
\hline Peroxyde value (meq $\mathrm{O}_{2} / 100 \mathrm{~g}$ ) & $16.0 \pm 0.5$ & $25.0 \pm 0.4$ \\
\hline $\mathrm{K}^{\mathrm{a}}{ }_{232}$ & $0.54 \pm 0.01$ & $0.90 \pm 0.01$ \\
\hline $\mathrm{K}^{\mathrm{a}}{ }_{270}$ & $0.66 \pm 0.01$ & $0.82 \pm 0.02$ \\
\hline lodine value $(\mathrm{g} / 100 \mathrm{~g})$ & $45.5 \pm 0.2$ & $44.1 \pm 0.3$ \\
\hline
\end{tabular}

${ }^{\mathrm{a}} \mathrm{K}_{2 \mathrm{3} 2}$ and $\mathrm{K}_{270}$ : specific extinction coefficients at $232 \mathrm{~nm}$ and $270 \mathrm{~nm}$ respectively. oil varies from $100 \mathrm{mg} / \mathrm{kg}$ to $1000 \mathrm{mg} / \mathrm{kg}$ (Tuck and Hayball, 2002). This may explain that date seed oil presented comparable oxidation induction times $(\sim 33-44 \mathrm{~h})$ to virgin olive oil (Besbes et al., 2004).

Date seed oils had a low refractive index indicating that they may contain fatty acids with medium-short hydrocarbon chains. Viscosity of date seed oil is one of the lowest among most vegetable oils but similar to that of oleic acid and raspberry seed oil (Oomah et al., 2000). This also suggested that date seed oil had a high medium-short chain fatty acids and triglycerides contents. In fact, a trend in the relationship between fatty acids chain length and viscosity was observed (Geller and Goodrum, 2000; Gustone et al., 1986).

The acidity and free fatty acids (FFA) were similar to those reported by Devshony et al. (1992) and ElShurafa et al. (1982). FFA contents of Deglet Nour seed oil were similar to that of extra-virgin olive oil for which the upper threshold limit is $1 \%$ free acidity. The low free-FFA content of date seed oil indicated that it could be edible. Allig seed oil had higher acidity, peroxide value and $\mathrm{K}_{232}, \mathrm{~K}_{270}$ extinctions coefficients compared to Deglet Nour seed oil. This may be due to the higher stability of Deglet Nour seed oil during the extraction procedure.

Iodine value ranged from $\sim 44.1$ for Deglet Nour to $\sim 45.5$ for Allig. These values were within ranges with those for date palm pits (Devshony et al., 1992; ElShurafa et al., 1982), but lower than those for olive oil, almond oil, sesame oil, soya oil and sunflower oil (Pearson, 1972). This may be due to the fact that date seed oil contained less polyunsaturated fatty acids (PUFA).

\section{Date Seed Oil's Lipid Classes}

Edible fats and oils are a complex mixture of triglycerides (TG: 90-95\%), diglycerides (DG: 1-2\%), free fatty acids (FFA: $\sim 0.5 \%$ ), phospholipids (PL) and other minor components $(-2.5 \%$ in the case of oil and $10 \%$ in the case of animal fats; Ruiz-Gutiérrez and Pérez-Camino, 2000).

Like all vegetable oils, triglycerides fraction of date seed oil represented the major part of the lipid fraction (97.26\% for Deglet Nour and $96.90 \%$ for Allig, Table 2). These proportions were slightly lower to those of olive oil $(98.5 \%-99 \%)$.

Sterol fraction was considered as the major unsaponifiable fraction in many oils. A high level of sterols were determined in both date seed oils, which made up about $0.35 \mathrm{~g} / 100 \mathrm{~g}$ Deglet Nour seed oil and about $0.30 \mathrm{~g} / 100 \mathrm{~g}$ in Allig seed oil. Sterols are related to the quality of oils, and the quantification of individual sterol components is fundamental to check authenticity (Salvador et al., 2001; Lercker and Rodriguez-Estrada, 2000). Authenticity of oil mean sterols content in date seed oils was higher compared 
Table 2. Lipid classes of date seed oils.

\begin{tabular}{lcc}
\hline & \multicolumn{2}{c}{ Cultivars } \\
\cline { 2 - 3 } Lipid Classes & Deglet Nour & Allig \\
\cline { 2 - 3 } & $(\mathrm{g} / 100 \mathrm{~g}$ Oil, Mean $\pm \mathrm{SD}, n=3)$ \\
\hline Neutral lipids & $98.30 \pm 0.54$ & $97.40 \pm 0.88$ \\
Triglycerides & $97.26 \pm 0.49$ & $96.90 \pm 0.50$ \\
Diglycerides & $0.23 \pm 0.07$ & $0.20 \pm 0.05$ \\
Monoglycerides & $0.09 \pm 0.01$ & $0.13 \pm 0.03$ \\
Free fatty acids & $0.33 \pm 0.07$ & $0.55 \pm 0.05$ \\
Phospholipids & $0.25 \pm 0.05$ & $0.18 \pm 0.02$ \\
Sterols & $0.36 \pm 0.04$ & $0.31 \pm 0.08$ \\
\hline
\end{tabular}

to extra virgin olive oil ( $\sim 0.15 \mathrm{~g} / 100 \mathrm{~g}$, Salvador et al., 2001). Both date seed oils studied have a good freshness state regarding their low content in free fatty acids, monoglycerids and diglycerids. Deglet Nour seed oil showed a slightly lower FFA $(0.33 \mathrm{~g} / 100 \mathrm{~g}$ oil against $0.55 \mathrm{~g} / 100 \mathrm{~g}$ oil, respectively). This confirmed the results obtained previously by official methods. Fractionation of lipid classes by solid fat extraction (SPE) could be very important to study functional properties of each date seed oil fraction such as emulsifying properties of phospholipids and monoglycerids.

\section{Fatty Acid Composition}

The major fatty acid found in both cultivars was oleic acid, ranging from $39.17 \%$ for Deglet Nour seed oil to $42.13 \%$ for Allig seed oil (Table 3 ). This was in agreement with what was reported in literature (AlShowiman, 1990; Devshony et al., 1992; Al-Hooti et al., 1998). However, Al-Hooti et al. (1998) found a higher content of oleic acid (53.3-58.8\%) in date seed oil from other origins. Fatty acid composition of date seed oil seemed to vary slightly with cultivars.

Deglet Nour and Allig seeds oil may be regarded as an oleic-lauric oil because oleic acid was the most abundant followed by lauric acid. Al-Hooti et al. (1998) also reported that date seed oils were oleic and linoleic, or oleic and palmitic. In a previous study Deglet Nour seed oil was regarded as an oleic-lauric oil, while Allig seed oil was an oleic-linoleic oil. The few differences between our previous results and the present ones, for Allig seed oil, may be explained by differences in climatic conditions from year to year. In general, fatty acid composition of date seed oils may be affected by differences between varieties, cultural conditions and climatic conditions (Al-Shahib and Marshall, 2003).

It is worth noting that the degree of unsaturation of these date seed oils was lower than that of common seed oils, since date seed fat had much lower linoleic acid content. In spite of this low level of unsaturation, date seed oil may present an interesting potential for different uses. In fact, Al-Shahib and Marshall (2003)
Table 3. Fatty acid composition of date seed oils.

\begin{tabular}{lcc}
\hline & \multicolumn{2}{c}{ Cultivars } \\
\cline { 2 - 3 } Fatty Acid & \multicolumn{2}{c}{ Allig } \\
\cline { 2 - 3 } & Deglet Nour & \\
\cline { 2 - 3 } & (g/100g Total Fatty Acids, Mean $\pm \mathrm{SD}, n=3)$ \\
\hline Capric C10 & $0.68 \pm 0.04$ & $0.44 \pm 0.01$ \\
Lauric C12 & $24.34 \pm 1.06$ & $22.56 \pm 0.36$ \\
Myristic C14 & $11.17 \pm 0.70$ & $10.33 \pm 0.04$ \\
Myristoleic C14 & - & $0.33 \pm 0.09$ \\
Palmitic C16 & $8.47 \pm 0.29$ & $8.30 \pm 0.08$ \\
Palmitoleic C16 & $0.18 \pm 0.08$ & $0.12 \pm 0.02$ \\
Stearic C18 & $2.57 \pm 0.25$ & $2.65 \pm 0.06$ \\
Oleic C18 & $39.17 \pm 0.62$ & $42.13 \pm 0.91$ \\
Linoleic C18 & $11.99 \pm 0.44$ & $11.66 \pm 0.07$ \\
Linolenic C18 & $1.39 \pm 0.88$ & $1.01 \pm 0.30$ \\
SAFA & $47.23 \pm 0.96$ & $44.29 \pm 0.66$ \\
MUFA & $39.34 \pm 1.10$ & $42.58 \pm 1.15$ \\
PUFA & $13.39 \pm 1.62$ & $12.67 \pm 0.68$ \\
\hline
\end{tabular}

- SAFA: saturated fatty acids, MUFA: monounsaturated fatty acids, PUFA: polyunsaturated fatty acid.

suggested that date seeds would be a useful source of edible oils for human consumption or for medicinal use.

\section{Triglyceride Composition}

The most abundant triglycerides fraction was $\mathrm{C} 48$ followed in descending order by C42, C44, C46, C50, C52, C54, C38 and C40 (Table 4). Both date seed oils presented a high content of medium molecular weight triglycerides (C32-C42) which ranged from $26.46 \%$ to $27.24 \%$ for Deglet Nour and Allig, respectively. Palm oil and soya oil were rather constituted by high molecular weight triglycerides (100\% C46-C54 for palm oil and 100\% C50-C56 for soya oil) (Collomb et al., 1998).

The presence of medium molecular weight triglycerides in date seeds oils reflect the presence of medium and short chain fatty acids (especially lauric acid)

Table 4. Triglycerides composition of date seed oils.

\begin{tabular}{lcc}
\hline & \multicolumn{2}{c}{ Cultivars } \\
\cline { 2 - 3 } Triglycerides & Deglet Nour & Allig \\
\cline { 2 - 3 } & \multicolumn{2}{c}{$(\mathrm{g} / 100 \mathrm{~g}$ total fatty acids, mean $\pm \mathrm{SD}, n=2)$} \\
\hline Total C38 & 4.87 & 4.94 \\
Total C40 & 2.60 & 2.80 \\
Total C42 & 18.99 & 19.50 \\
Total C44 & 15.83 & 16.48 \\
Total C46 & 14.88 & 15.59 \\
Total C48 & 22.68 & 21.13 \\
Total C50 & 8.94 & 8.87 \\
Total C52 & 5.46 & 5.35 \\
Total C54 & 4.87 & 4.01 \\
\hline
\end{tabular}


which were responsible for the low viscosity of date seed oil.

Regarding differences between triglyceride composition of oils, triglyceride profile of date seed oil could also be used to check authenticity.

\section{Effect of Storage at $60^{\circ} \mathrm{C}$}

Quality indexes such as specific extinctions at $232 \mathrm{~nm}$ and $270 \mathrm{~nm}$, and chlorophylls content were followed up in order to study the effect of storage in accelerated conditions (oven test at $60^{\circ} \mathrm{C}$ ) on date seed oil. Figures 1 and 2 display the relationship between heating time at $60^{\circ} \mathrm{C}$ and specific extinctions and chlorophylls content.

The formation of primary compounds of oxidation such as hydroperoxides coincided with the increase of absorptivity at $232 \mathrm{~nm}$. Formation of primary compounds of oxidation occurred initially at a lower rate. In fact, the extinction coefficient at $232 \mathrm{~nm}$ passed only from $\sim 0.6$ to $\sim 3.8$. This little increase suggested that date seed oils were resistant to oxidation. After only 6 days in the same conditions, absorptivity at $232 \mathrm{~nm}$ of canola oil reached about 10.26 (Vieira and Regitanod'Arce, 2001). After 50 days in an oven, specific extinction at $232 \mathrm{~nm}$ became much higher for Allig seed oil. This may be explained by the fact that Deglet Nour seed oil was more resistant to oxidation. In fact, in a previous work on Allig seed oil presented a lower induction time ( $33 \mathrm{~h}$ against $44 \mathrm{~h}$, Besbes et al., 2004). The primary products of oxidation are not stable under heating and then their degradation could promote the formation of secondary product of oxidation that absorb at about $270 \mathrm{~nm}$ (Vieira and Regitano-d'Arce,

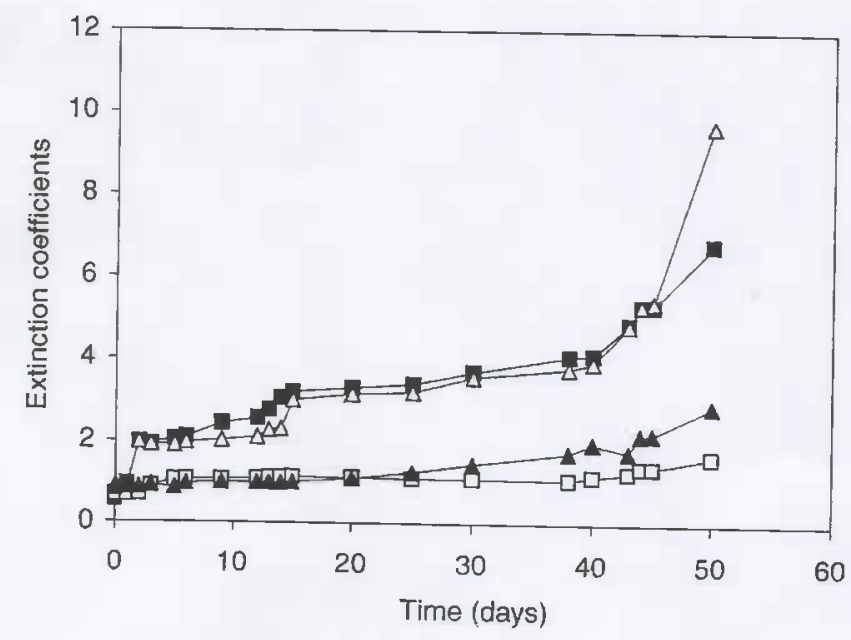

Figure 1. Relationship between specific extinctions and heating time during thermal oxidation of date oil

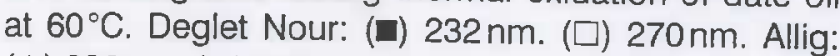
$(\triangle) 232 \mathrm{~nm}$. (A) $270 \mathrm{~nm}$.

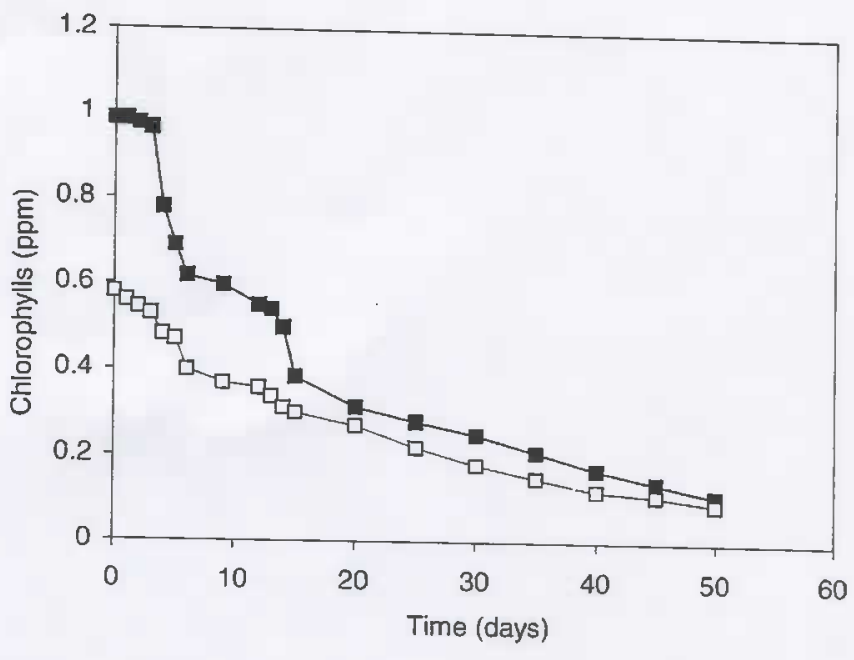

Figure 2. Relationship between chlorophylls content and heating time during thermal oxidation at $60^{\circ} \mathrm{C}$. (घ): Deglet Nour. ( $\square$ ) Allig.

2001). Specific extinction at $270 \mathrm{~nm}$ did not considerably change during 50 days in an oven (Figue 1). This also confirmed the resistance of date seed oil against the oxidative phenomenon. This resistance against oxidation of date seed oil may be explained firstly because date seed oil presented a low polyunsaturated fatty acid content, which are more sensitive to oxidation, and secondly by the presence of natural antioxidant such as phenolic compounds, sterols, tocopherols and chlorophylls (Besbes et al., 2004).

Despite differences in their initial chlorophyll content, Deglet Nour and Allig seed oil showed similar chlorophyll deterioration. Chlorophylls content of both date seed oils decreased considerably during storage at $60^{\circ} \mathrm{C}$. This decrease could be due to thermal oxidation or to the destruction of these pigments. The study of the pro-oxidant or antioxidant activity of date seeds oil's chlorophylls would require the analysis of different type of pigments.

The results indicate the potential functional and economic utility of Phoenix dactylifera $L$. date seeds as a new source of oils. All these characteristics consolidate the possibility of date seed oil incorporating into food and cosmetics, and its pharmaceutical applications. Nevertheless, it is very important to support this study by integrating date seeds oils in some food and cosmetic formulations.

\section{REFERENCES}

Al-Hooti S., Sidhu J.S. and Qabazard H. (1998). Chemical composition of seeds date fruit cultivars of United Arab Emirates. Journal of Food Science and Technolgy 35: 44-46. 
Almana H.A. and Mahmoud R.M. (1994). Palm date seed as an alternative source of dietary fiber in Saudi bread. Ecology of Food and Nutrition 32: 261-270.

Al-Shahib W. and Marshall R.J. (2003). Fatty acid content of the seeds from 14 varieties of date palm Phoenix dactylifera L. International Journal of Food Science and Technology 38: 709-712.

Al-Showiman S.S. (1990). Chemical composition of date palm seeds (Phoenix dactylifera L.) in Saudi Arabia. Journal of Chemistry Society 12: 15-24.

AOCS (1997). Official Methods and Recommended Practices of the American Oil Chemists' Society. 5th edn, Champaign, USA: AOCS Press.

AOAC (1997). Official Methods of Analyses. Washington. DC: AOAC.

Banat F., Al-Asheh S. and Al-Makhadmeh L. (2003). Evaluation of the use of raw and activated date pits as potential adsorbent for dye containing waters. Process Biochemistry 00: 1-10.

Besbes S., Blecker C., Deroanne C.. Drira N. E. and Attia H. (2004). Date seeds: chemical composition and characteristic profiles of the lipid fraction. Food Chemistry 84: 577-584.

Caponio F., Alloggio V. and Gomes T. (1999). Phenolic compounds of virgin olive oil: influence of paste preparation techniques. Food Chemistry 64: 203-209.

Collomb M., Spabni M. and Bubler T. (1998). Analyse des triglycérides: I. Optimisation et validation d'une méthode GC rapide et application à diverses graisses végétales et animales. Travaux du Chimie des Aliments et Hygiène 89: 59-74.

Devshony S., Eteshola A. and Shani A. (1992). Characterisation and some potential application of date palm (Phoenix dactylifera L.) seeds and seeds oil. Journal of American Oil Chemist's Society 69: 595-597.

El-Shurafa M.Y., Ahmed H.S. and Abou-Naji S.E. (1982). Organic and inorganic constituent of dates palm pits (seeds). Journal of Date Palm 2: 275-284.

Geller D.P. and Goodrum, J.W. (2000). Rheology of vegetable oil analogs and triglycerides. Journal of American Oil Chemist's Society 77: 111-114.

Girgis B.S. and El-Hendawy A.-N. A. (2002). Porosity development in activated carbons obtained from date pits under chemical activation with phosphoric acid. Microporous and Mesoporous Materials 52: 105-117.

Gustone F.D., Harwood J.L. and Padley F.B. (1986). The Lipid Handbook. London: Chapman and Hall, pp. 81.

Hamada J.S.. Hashim I.B. and Sharif A.F. (2002). Preliminary analysis and potential uses of date pits in foods. Food Chemistry 76: 135-137.

Hussein A.S. Alhadrami G.A. and Khalil Y.H. (1998). The use of dates and date pits in broiler starter and finisher diets. Bioresource Technology 66: 219-223.
Ishrud O., Ali Y., Wei W., Bashir F., Ali A., Ashour A. and Pan Y. (2003). An alkali-soluble heteroxylan from seeds of phoenix dactylifera $L$. Carbohydrate Research 338: 1609-1612.

Ishrud O., Zahid M., Zhou H. and Pan Y. (2001). A water-soluble galactomannan from the seeds of Phoenix dactylifera L. Carbohydrate Research 335: 297-301.

Lercker G. and Rodriguez-Estrada M.T. (2000). Chromatographic analysis of unsaponifiable compounds of olive oils and fat-containing foods. Journal of Chromatography 881: 105-129.

Montedoro G., Servilli M., Baldioli M., Selvaggini R., Miniati E. and Macchioni A. (1993). Simple and hydrolyzable compounds in virgin olive oil. Spectroscopic characterizations of the secoiridoid derivatives. Journal of Agricultural and Food Chemistry 41: 2228-2234.

Nissiotis M. and Tasioula-Margari M. (2002). Changes in antioxydant concentration of virgin olive oil during thermal oxidation Food Chemistry 77: 371-376.

Oomah B.D.. Ladet S., Godfrey D.V., Liang J. and Girard B. (2000). Characteristics of raspherry (Rubus idaeus L.) seed oil. Food Chemistry 69: 187-193.

Papadopoulus G. and Boskow D. (1991). Antioxidant effect of natural phenols on olive oil. Journal of American Oil Chemist's Society 68: 669-671.

Pearson D. (1972). Laboratory Techniques in Food Analysis, 6th edn, London: Churchill.

Ruiz-Gutiérrez V and Pérez-Camino M.C. (2000). Update on solid-phase extraction for the analysis of lipid classes and related compounds. Journal of Chromatography A 885: 321-341.

Salvador M.D., Aranda F., Gomez-Alonso S. and Fregapane G. (2001). Cornicabra virgin olive oil: a study of five crop seasons. Composition, quality and oxidative stability. Food Chemistry 74: 267-274.

Salvador M.D., Aranda F., Gomez-Alonso S. and Fregapane G. (2003). Influence of extraction system, production year and area on Cornicabra virgin olive oil: a study of five crop seasons. Food Chemistry 80: 359-366.

Tuck K.L. and Hayball P.J. (2002). Major phenolic compounds in olive oil: metabolism and health effects. Journal of Nutritional Biochemistry 13: 636-644.

Vaghela M.N. and Kilara A. (1995). A rapid method for extraction of total lipids from whey protein concentrates and separation of lipid classes with solid phase extraction. Journal of American Oil Chemist's Society 72: 1117-1119.

Vieira T.M.F.S. and Regitano-d'Arce M.A.B. (2001). Canola oil thermal oxidation during oven test and microwave heating. Lebensmittel-Wissenschaft-undTechnologie 34: 215-221. 